\title{
Lipoma del cuerpo calloso con crisis convulsiva que ocasiona broncoaspiración alimentaria mortal.
}

\author{
Lipoma of the corpus callosum with seizure which \\ causes fatal alimentary aspiration.
}

J. Lucena y cols.

Cuad Med Forense 2004; 37:59-63

Varón de 42 años con antecedentes de dos crisis tónico-clónicas previas a los 28 y 40 años. A raíz de la última crisis se realizaron estudios complementarios (EEG, TAC y RNM craneal) que pusieron de manifiesto "grasa en el cerebro", según explicó la familia. No se indicó ningún control ni tratamiento antepiléptico. Mientras cenaba en su domicilio presentó nueva crisis tónico-clónica seguida de insuficiencia respiratoria y parada cardíaca que no se consigue reanimar. La autopsia puso de manifiesto abundante material alimenticio en bronquios y brinquiolos. Los pulmones presentaban edema generalizado con áreas de hemorragia focal. Estudio neuropatológico: encéfalo de 15 I 5 g congestivo y edematoso. Se observan dos lipomas curvilíneos situados en la parte superior de la rodilla del cuerpo calloso $(2,5 \times 0,7 \mathrm{~cm}$ y I,5 × 0,5 $\mathrm{cm}$, respectivamente) constituidos por tejido adiposo maduro y muy bien vascularizados (Fig, I y 2).

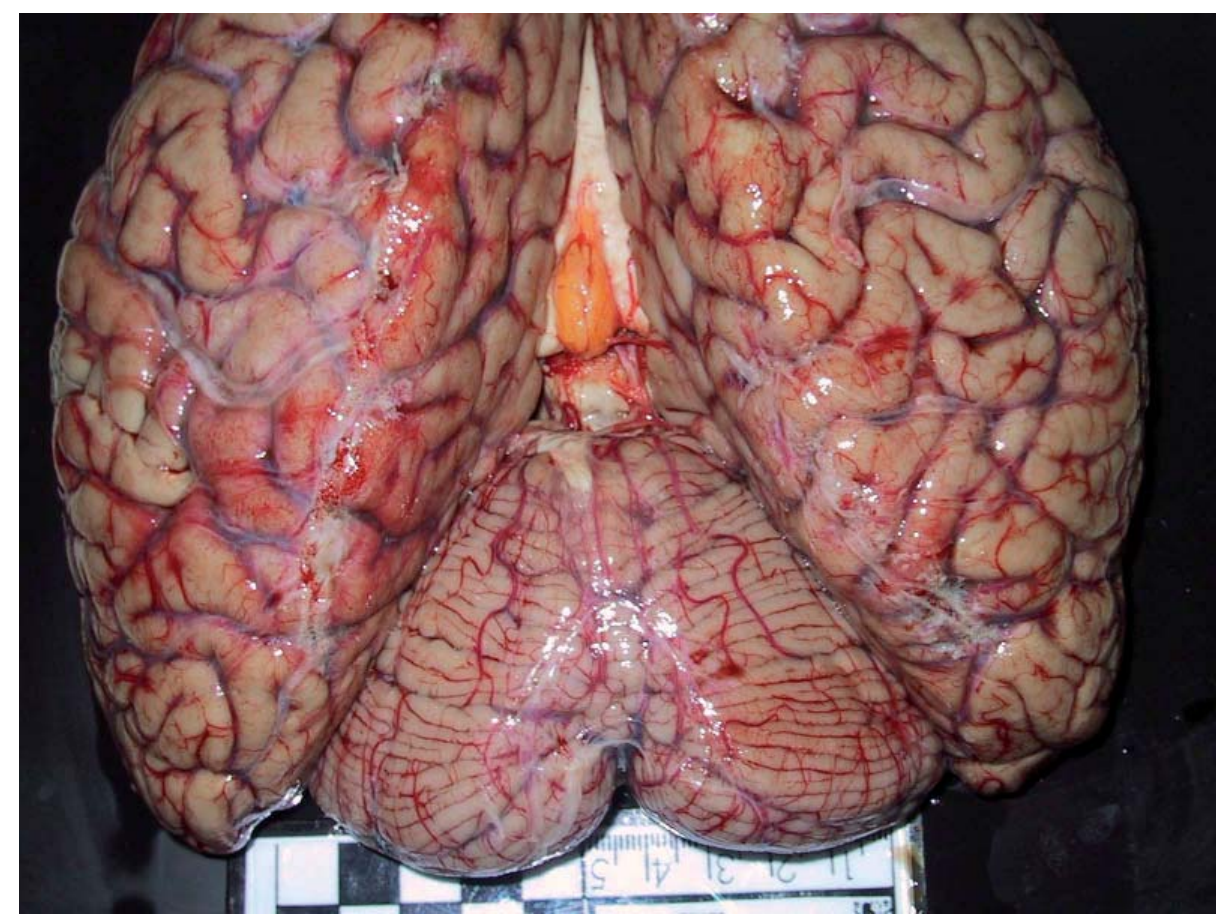

Figura 1.- Examen macroscópico del encéfalo en fresco en el que se aprecia una masa de aspecto lipomatoso situada en la parte interhemisféfica posterior. 


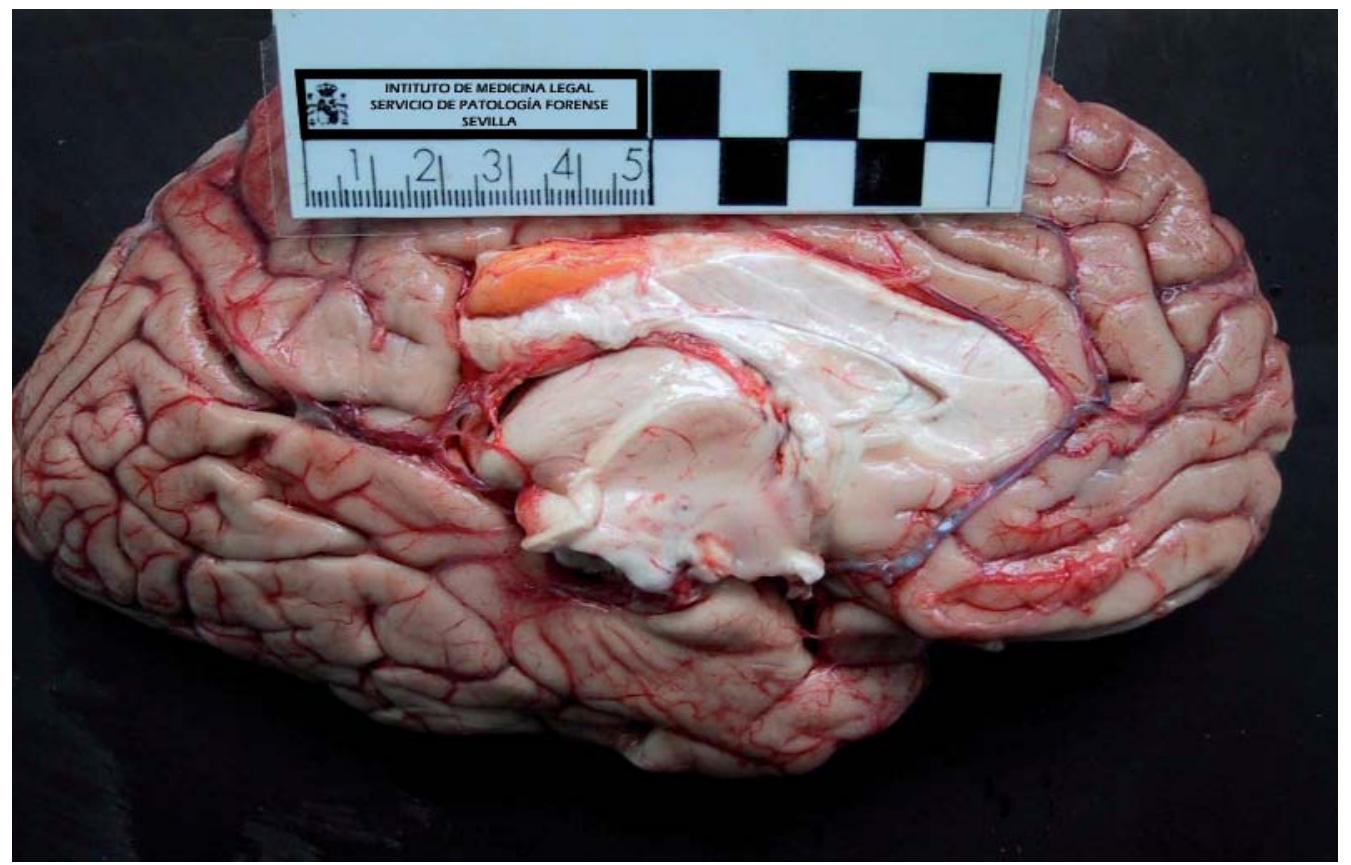

Figura 2.- Examen macroscópico en fresco del hemisferio izquierdo donde se aprecia el lipoma en la rodilla del cuerpo calloso.

No estaban asociados a anomalías en el desarrollo del cuerpo calloso. El estudio histopatológico confirmó que se trataba de lipomas constituidos por tejido adiposo típico y maduro envueltos por una cápsula de fibras colágenas que, en los puntos de contacto con el tejido nervioso, penetraba en el parénquima cerebral en asociación con vasos sanguíneos (Fig.3). Se estableció el diagnóstico definitivo de lipomas del cuerpo calloso que se manifestaron clínicamente con crisis comicial y en el curso de la misma se produjo una aspiración respiratoria de material alimentario que provocó la muerte.

Fig. 3.- Estudio histopatológico que pone de manifiesto tejido adiposo típico y maduro envuelto por una cápsula de fibras colágenas que, en los puntos de contacto con el tejido nervioso, penetra en el parénquima cerebral en asociación con vasos sanguíneos (HE x 20).

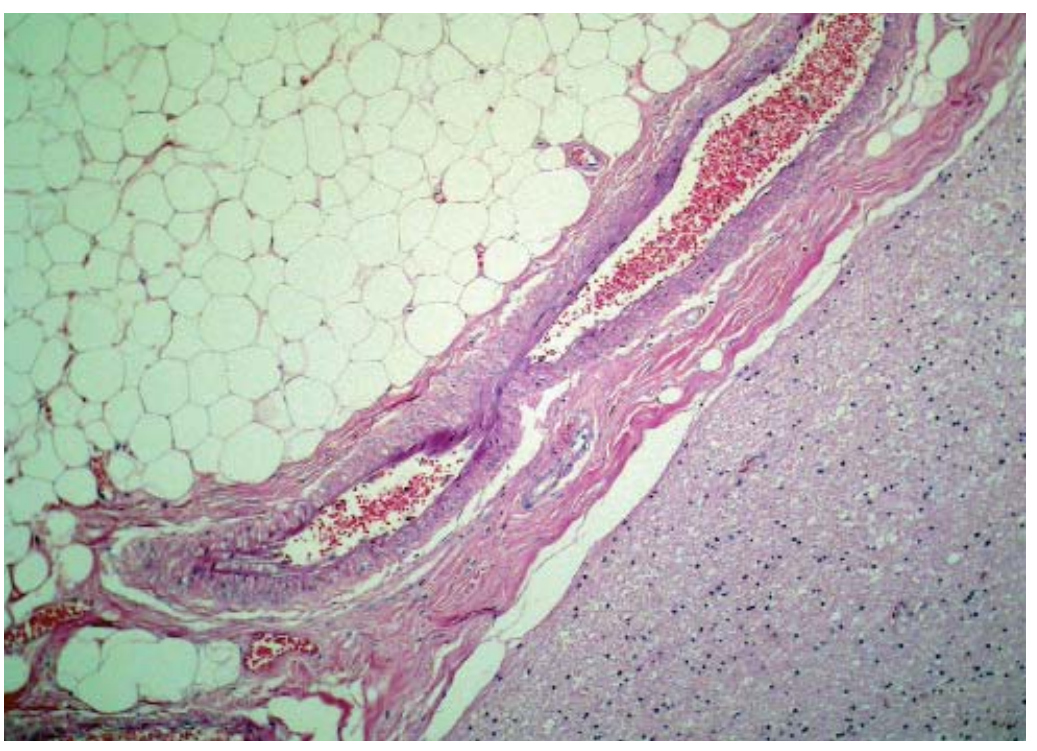

